\title{
Ajuste do rendimento para a variação do estande em experimentos de melhoramento genético do feijão
}

\author{
Clause Fátima de Brum Piana ${ }^{(1)}$, João Gilberto Corrêa da Silva(1) e Irajá Ferreira Antunes(2)
}

\begin{abstract}
(1)Universidade Federal de Pelotas, Campus Universitário, s/no, Caixa Postal 354, CEP 96010-900 Pelotas, RS. E-mail: clause@ufpel.edu.br, jgcs@ufpel.edu.br (2)Embrapa Clima Temperado, BR 392, Km 78, Campus Universitário, Caixa Postal 403, CEP 96001-970 Pelotas, RS. E-mail: iraja@cpact.embrapa.br
\end{abstract}

\begin{abstract}
Resumo - O objetivo deste trabalho foi avaliar o ajuste do rendimento pela variação do estande em experimentos de feijão e propor procedimento para ajustamento por análise de co-variação. Utilizaram-se dados de 33 ambientes do Ensaio Estadual de Feijão do Rio Grande do Sul. Realizaram-se as análises de variação e de co-variação de rendimento e de estande em cada ambiente. Foram considerados quatro modelos de ajustamento alternativos: sem ajuste para a variação do estande; com ajuste para o estande médio geral; com ajuste para os estandes médios dos genótipos; e com ajuste para os estandes médios dos grupos de genótipos. Em 70\% dos ambientes, ocorreu efeito linear ou quadrático significativo de estande sobre rendimento e em $85 \%$ efeito significativo de genótipo sobre estande. $\mathrm{O}$ efeito compensatório manifestou-se com diferentes intensidades nos ambientes. $\mathrm{O}$ ajuste do rendimento para a variação do estande, considerando o efeito de genótipos sobre o estande, é importante em ensaios de melhoramento do feijão. É necessário o registro de informações que permitam discriminar a origem da variação do estande.
\end{abstract}

Termos para indexação: Phaseolus vulgaris, análise de co-variação, precisão experimental, validade do experimento.

\section{Adjustment of the yield for the stand variation in common bean genetic breeding experiments}

\begin{abstract}
The objective of this work was to evaluate the adjustment of the yield for the stand in common bean experiments and to propose a procedure for the adjustment through covariance analysis. Data from 33 environments of the Common Bean Assay of Rio Grande do Sul State, Brazil, were used. Variance and covariance analyses of yield and stand were proceeded for each environment. Four alternative models were considered: without adjustment for stand; with adjustment for the average stand; with adjustment for the genotypes average stand; and with adjustment for the groups of genotypes average stand. Significant linear or quadratic effects of stand on yield occurred in $70 \%$ of the environments and of genotype on stand in $85 \%$. The compensatory effect was manifested with different intensities in the environments. The adjustment of the yield for stand, considering the effect of genotypes on stand, is important in common bean experiments. The record of information to discriminate the origins of the variation of stand is necessary.
\end{abstract}

Index terms: Phaseolus vulgaris, covariance analysis, experimental precision, validity of the experiment.

\section{Introdução}

Em programas de melhoramento de plantas, a etapa de avaliação é a mais demorada e de maior custo. Por essa razão, experimentos de competição de cultivares devem ter precisão e validade apropriadas para que as diferenças fenotípicas representem os efeitos genotípicos e de ambiente. Um fator que afeta a qualidade de experimentos é a perda de plantas na parcela, com prejuízo para a precisão (Veronesi et al., 1995) e a validade (não tendenciosidade) das inferências.
Uma técnica que tem sido utilizada para contornar esse problema é a correção ou ajuste do rendimento de grãos para a variação do estande final.

Métodos de ajuste do rendimento para a variação do estande têm sido referidos na literatura. Entre eles, destacam-se: ajuste com base no estande ideal por regra de três simples; acréscimo de $70 \%$ do rendimento médio por planta para cada falha (Zuber, 1942); ajuste com base no estande médio; ajuste com base no estande ideal; e ajuste estratificado com base no agrupamento de genótipos segundo o estande. Os três últimos são feitos 
por análise de co-variação (Vencovsky \& Cruz, 1991; Veronesi et al., 1995; Storck et al., 2000; Schmildt et al., 2001; Cargnelutti Filho \& Storck, 2004; Andrade et al., 2006).

Vencovsky \& Cruz (1991) argumentam que o rendimento, em geral, não é proporcional ao número de plantas na parcela e que, para alcançar uma correção não tendenciosa, é necessário considerar tanto o decréscimo na produção pela presença de falhas como o acréscimo pelas plantas vizinhas às falhas, resultante da ausência de competição. Observam também que o propósito de identificar um método de ajuste superior aos demais, nas diversas situações experimentais, apresenta dificuldades em face do desconhecimento da capacidade compensatória média real dos genótipos avaliados.

Algumas espécies, entre elas o feijão, manifestam efeitos compensatórios dos componentes do rendimento, quando cultivadas com densidades menores que as recomendadas (Adams, 1967; Fernandes et al., 1989). Pesquisas têm sido realizadas a fim de compreender os efeitos da densidade de semeadura e do espaçamento entre linhas sobre o rendimento do feijão e seus componentes, algumas delas considerando, também, os efeitos do hábito de crescimento e do tipo de planta (Valério et al., 1999; Jadoski et al., 2000; Shimada et al., 2000; Teixeira et al., 2000; Didonet \& Costa, 2004). Essas pesquisas têm evidenciado que alterações na população de plantas podem ser compensadas pelos componentes primários do rendimento (número de vagens por planta, número de grãos por vagem e massa de grãos).

$\mathrm{Na}$ avaliação da influência da perda de plantas sobre a produção em duas cultivares de feijão, CNF-005 (tipo II) e Pintado (tipo III), Fernandes et al. (1989) concluíram que não havia diferença entre os efeitos de falhas na parcela nesses dois tipos de planta, sobre as variáveis número de vagens por planta, produção de grãos por planta e produção de grãos por área. Observaram, também, que a regressão da produção de grãos em relação ao estande não foi significativa, mas a regressão do número de vagens em relação ao número de grãos por planta foi significativa, o que evidencia a existência de compensação da produção pelas plantas restantes. Segundo Adams (1967), maior competição entre plantas pode induzir maior competição dentro da planta para os assimilados, o que conduz a um efeito compensatório dos componentes de produtividade do feijão, que determina o rendimento de grãos.
Ribeiro et al. (2004a, 2004b) relatam experimentos com objetivo tanto de estudar a ocorrência de possíveis modificações fenológicas e morfológicas em caracteres importantes na seleção de genótipos superiores de feijão, oriundas de alterações na densidade de plantas, como também de identificar a porcentagem máxima possível de redução da densidade de plantas sem diminuição da precisão experimental. Ribeiro et al. (2004a) observaram que as cultivares de feijão têm seus caracteres fenológicos e morfológicos alterados de maneira diferenciada de acordo com a densidade de plantas. Concluíram que as plantas de feijão manifestam efeito compensatório dos componentes do rendimento de grãos e atribuíram essa compensação aos aumentos do número de vagens e do número de grãos por planta. Ribeiro et al. (2004b) verificaram que a precisão experimental foi alterada com as mudanças dos níveis de redução da densidade de plantas e que a maior precisão ocorreu em ensaios sem redução da densidade de plantas.

O objetivo deste trabalho foi avaliar o ajuste do rendimento para a variação do estande em experimentos de melhoramento genético do feijão e propor procedimento para ajustamento por análise de co-variação.

\section{Material e Métodos}

Foi utilizada parte dos dados relativos a um período de oito anos de execução do Ensaio Estadual de Feijão (EEF), coordenado pela Comissão Estadual de Pesquisa de Feijão (CEPEF) do Rio Grande do Sul. Esses dados provêm dos 33 ambientes, combinações de ano e local, onde o estande final por parcela foi registrado. Os ambientes compreendem 16 locais - Arroio do Tigre, Frederico Westphalen, Canguçu, Capão do Leão, Cruz Alta, Coronel Bicaco, Erechim, Iraí, Júlio de Castilhos, Osório, Passo Fundo, Pelotas, Santa Maria, Santo Augusto, Sarandi e Sobradinho - e oito anos, safras 1987/1988 a 1994/1995. Os conjuntos de genótipos variaram entre esses anos. Em cada ambiente, foi empregado o delineamento em blocos completos casualizados com quatro repetições. A condução dos experimentos seguiu as recomendações técnicas para o cultivo do feijão (Instituto de Pesquisas Agronômicas, 1986).

Na semeadura, procedida manualmente, foi adotada a densidade de 240 mil plantas por hectare, o que equivale a 12 plantas por metro linear com espaçamento de $0,5 \mathrm{~m}$ entre linhas. A área útil da parcela foi constituída por duas linhas de $3 \mathrm{~m}$, correspondendo a 72 plantas. A fim 
de alcançar a uniformidade do estande inicial, foi efetuado ajuste do número de sementes com base em teste de germinação.

Inicialmente, foi realizada análise da variação do rendimento em cada um dos ambientes, de acordo com o Modelo 1, sem ajuste do rendimento para o estande, com a seguinte equação: $y_{i j}=\mu+b_{j}+g_{i}+e_{i j}, i=1,2, \ldots, g$; $\mathrm{j}=1,2, \ldots, \mathrm{b}$, em que $y_{\mathrm{ij}}$ é o rendimento observado na parcela do bloco $\mathrm{j}$ com o genótipo i; $\mu$ é a média geral esperada; $b_{j}$ é o efeito aleatório do bloco $\mathrm{j} ; \mathrm{g}_{\mathrm{i}}$ é o efeito fixo do genótipo i; $\mathrm{e}_{\mathrm{ij}}$ é o desvio entre os rendimentos observado e esperado na parcela ij.

Foram realizadas as análises de co-variação, por ambiente, entre rendimento e estande final, a fim de verificar a existência de relação polinomial linearquadrática entre essas variáveis e testar a hipótese de homogeneidade dos coeficientes de regressão dos genótipos. Os resultados dessas análises fundamentaram a decisão de ajustar ou não o rendimento pelo estande e orientaram a escolha do grau da função polinomial a ajustar em cada ambiente.

Considerando-se que a interação estande $\mathrm{x}$ genótipo foi significativa em um número de ambientes relativamente pequeno, foi adotado como procedimento geral para ajustamento do rendimento a análise de co-variação com coeficiente de regressão comum para os genótipos.

Em cada ambiente em que foi realizado o ajustamento, adotou-se um dos dois seguintes modelos alternativos: modelo linear (L) e modelo linear-quadrático (LQ). $\mathrm{O}$ primeiro foi adotado quando apenas o efeito linear do estande foi significativo e o segundo, quando o efeito quadrático do estande também foi significativo.

Quanto à decisão sobre o modelo de análise de covariação específico a adotar em cada ambiente, foi realizada análise da variação do estande final, previamente submetido à transformação para raiz quadrada, para testar a significância da variação do estande entre genótipos, segundo equação semelhante à do Modelo 1. Essa variação expressa efeito de genótipos e, também, efeito do erro experimental confundido com efeito de genótipos. Assim, a significância desta fonte de variação pode decorrer tanto de efeito de genótipos propriamente quanto de efeito de erro experimental, resultante, por exemplo, de diferenças de estande inicial entre os genótipos.

Na sequiência, efetuou-se ajuste do rendimento para a média geral do estande, pelo procedimento usual de análise da co-variação, segundo o Modelo 2, com a seguinte equação: $L: y_{i j}=\mu+b_{j}+g_{i}+\beta\left(x_{i j}-\bar{x}\right)+e_{i j}^{\prime}$, ou LQ: $y_{i j}=\mu+b_{j}+g_{i}+\beta_{1}\left(x_{i j}-\bar{x}\right)+\beta_{2}\left(x_{i j}-\bar{x}\right)^{2}+e^{\prime}$, $\mathrm{i}=1,2, \ldots, \mathrm{g} ; \mathrm{j}=1,2, \ldots, \mathrm{b}$, em que $\beta, \beta_{1}$ e $\beta_{2}$ são coeficientes de regressão; $\mathrm{x}_{\mathrm{ij}}$ é o estande na parcela do bloco j com o genótipo i; $\bar{x}$ é a média geral do estande; $\mathrm{e}^{\prime}{ }_{\mathrm{ij}}$ é o desvio entre os rendimentos observado e esperado na parcela ij.

Este ajuste remove a variação do rendimento devida ao estande das estimativas dos efeitos de genótipos $\left(\mathrm{g}_{\mathrm{i}}\right)$ e do erro experimental ( $\left.e_{i j}^{\prime}\right)$. É apropriado quando a variação do estande final se deve exclusivamente ao erro experimental, como, por exemplo, às diferenças de estande inicial. Entretanto, ele não é adequado quando o estande é afetado por efeito de genótipos. Neste último caso, o ajustamento apropriado é proporcionado por análise de co-variação com base no Modelo 3, com ajuste do rendimento para as médias de estande dos genótipos, com a seguinte equação: $\mathrm{L}: \mathrm{y}_{\mathrm{ij}}=\mu+\mathrm{b}_{\mathrm{j}}+\mathrm{g}_{\mathrm{i}}+$ $\beta\left(x_{i j}-\bar{x}_{i}\right)+e^{\prime}{ }_{i j}$, ou LQ: $y_{i j}=\mu+b_{j}+g_{i}+\beta_{1}\left(x_{i j}-\bar{x}_{i}\right)+$ $\beta_{2}\left(\mathrm{x}_{\mathrm{ij}}-\overline{\mathrm{x}}_{\mathrm{i}}\right)^{2}+\mathrm{e}^{\mathrm{ij}}, \mathrm{i}=1,2, \ldots, \mathrm{g} ; \mathrm{j}=1,2, \ldots, \mathrm{b}$, em que $\overline{\mathrm{x}}_{\mathrm{i}}$ é $\mathrm{a}$ média do estande do genótipo i; $\mathrm{e}{ }_{\mathrm{ij}}$ é o desvio entre os rendimentos observado e esperado na parcela ij.

Este ajuste remove a variação decorrente do estande da estimativa do erro experimental ( $e{ }_{\mathrm{ij}}$ ), mas não da estimativa do efeito de genótipos $\left(\mathrm{g}_{\mathrm{i}}\right)$. É apropriado quando a variação do estande entre genótipos decorre exclusivamente de efeito de genótipos.

Para levar em conta diferenças de genótipos que são devidas apenas ao erro experimental, pode-se proceder ao agrupamento dos genótipos quanto a seus efeitos sobre o estande e, então, à análise da co-variação, segundo o Modelo 4, com ajuste do rendimento para as médias de estande dos grupos de genótipos, com a equação: $L: y_{i j}=\mu+b_{j}+g_{i}+\beta\left(x_{i j}-\bar{x}_{k}\right)+e^{\prime \prime}{ }_{i j}$, ou LQ: $y_{i j}=\mu+b_{j}+g_{i}+\beta_{1}\left(x_{i j}-\bar{x}_{k}\right)+\beta_{2}\left(x_{i j}-\bar{x}_{k}\right)^{2}+e^{\prime \prime}{ }_{i j}$, $\mathrm{i}=1,2, \ldots, \mathrm{g} ; \mathrm{j}=1,2, \ldots, \mathrm{b}$, em que $\overline{\mathrm{x}}_{\mathrm{k}}$ é a média do estande para o grupo de genótipos $\mathrm{k}$; e" ${ }^{1 j}$ é o desvio entre os rendimentos observado e esperado na parcela ij.

Este ajuste remove a variação decorrente do estande das estimativas do erro experimental e dos efeitos de genótipos de mesmo grupo, mas não das estimativas dos efeitos de grupos de genótipos. É apropriado quando a variação do estande entre genótipos decorre exclusivamente de efeito de grupos de genótipos.

$\mathrm{O}$ agrupamento dos genótipos, em cada um dos ambientes em que a variação do estande decorrente dos genótipos foi significativa, foi realizado com base no teste de Scott \& Knott (1974). Esse teste é mais conservador do que o teste $\mathrm{F}$, quanto à taxa de erro tipo 1. Para obter agrupamentos coerentes com os que seriam formados por teste F com nível de significância $\alpha=0,05$, efetuouse o teste de Scott-Knott com os níveis de significâncias $\alpha=0,05,0,10$ e 0,20 , para escolher o nível de significância apropriado.

A escolha do modelo apropriado a cada ambiente é baseada nos resultados dos testes de significância dos 
efeitos linear e quadrático do estande sobre o rendimento e da variação do estande causada por genótipos, e, no caso de significância dessa variação, no resultado do teste de Scott-Knott. No entanto, essa escolha deve ser fundamentada no conhecimento da origem da variação do estande entre genótipos, que pode ser os genótipos ou características estranhas associadas aos genótipos. Se a variação do estande entre genótipos decorre exclusivamente de efeito de características estranhas, deve-se optar pelo Modelo 2. Se a variação do estande entre genótipos decorre exclusivamente de efeito de genótipos, deve-se optar pelo Modelo 3 ou pelo Modelo 4.

As informações disponíveis sobre o conjunto de ambientes não permitem a identificação da origem da variação do estande entre os genótipos.

\section{Resultados e Discussão}

As estatísticas descritivas do estande final e o resumo dos resultados da análise da variação desta variável são apresentados para cada um dos 33 ambientes (Tabela 1). A análise descritiva do estande revelou que as médias por ambiente variaram de 23 a 84 plantas por parcela, correspondendo, respectivamente, a $68,1 \%$ e $-16,7 \%$ de redução em relação ao estande ideal (72 plantas por parcela). As médias de estande por genótipo mais extremas foram 14 (81,3\% de redução) e 98 (-35,4\% de redução) plantas por parcela. Segundo Ribeiro et al. (2004a), as cultivares de feijão podem compensar o rendimento de grãos quando há redução de até $60 \%$ na densidade de plantas. Levando em conta que foi adotado um método de ajuste da densidade de

Tabela 1. Estatísticas descritivas do estande e principais resultados das análises da variação de estande transformado por raiz quadrada, para os 33 ambientes.

\begin{tabular}{|c|c|c|c|c|c|c|c|c|c|}
\hline \multirow{4}{*}{$\begin{array}{l}\text { Ambiente }^{(1)} \\
\text { (ano-local) }\end{array}$} & \multicolumn{6}{|c|}{ Estatísticas descritivas } & \multicolumn{3}{|c|}{ Análise da variação } \\
\hline & \multirow{3}{*}{$\begin{array}{l}\text { Número de } \\
\text { observações }\end{array}$} & \multirow[t]{3}{*}{ Média } & \multicolumn{4}{|c|}{ Valores extremos } & \multirow{3}{*}{$\begin{array}{c}\mathrm{F} \\
\text { Genótipo }\end{array}$} & \multirow{3}{*}{$\begin{array}{l}\text { Prob. }>\text { F } \\
\text { Genótipo }\end{array}$} & \multirow[t]{3}{*}{ CV $(\%)$} \\
\hline & & & \multicolumn{2}{|c|}{ Por genótipo } & \multicolumn{2}{|c|}{ Por parcela } & & & \\
\hline & & & Inferior & Superior & Inferior & Superior & & & \\
\hline $1-1^{*}$ & 120 & 71 & 50 & 87 & 36 & 95 & 4,10 & $<0,0001$ & 7,6 \\
\hline $1-2$ & 120 & 70 & 43 & 86 & 21 & 99 & 5,39 & $<0,0001$ & 6,3 \\
\hline $1-3^{*}$ & 120 & 48 & 26 & 59 & 15 & 76 & 1,66 & 0,0371 & 13,5 \\
\hline $1-5^{*}$ & 120 & 84 & 64 & 98 & 51 & 112 & 3,44 & $<0,0001$ & 5,0 \\
\hline $1-6^{*}$ & 120 & 66 & 39 & 89 & 31 & 98 & 4,60 & $<0,0001$ & 8,5 \\
\hline $1-7^{*}$ & 120 & 51 & 64 & 98 & 9 & 82 & 2,31 & 0,0015 & 10,3 \\
\hline $2-2 *$ & 120 & 39 & 31 & 49 & 14 & 62 & 0,91 & 0,5997 & 12,1 \\
\hline $2-3^{*}$ & 102 & 60 & 35 & 64 & 34 & 85 & 1,76 & 0,0296 & 6,3 \\
\hline $2-5^{*}$ & 120 & 67 & 38 & 89 & 14 & 95 & 2,43 & 0,0008 & 13,0 \\
\hline $2-7$ & 90 & 56 & 37 & 70 & 16 & 80 & 1,81 & 0,0274 & 9,8 \\
\hline $2-8$ & 111 & 54 & 39 & 75 & 34 & 82 & 2,26 & 0,0026 & 8,1 \\
\hline $2-9 *$ & 120 & 65 & 48 & 79 & 32 & 89 & 1,53 & 0,0668 & 8,3 \\
\hline $2-10$ & 120 & 75 & 64 & 93 & 55 & 99 & 3,55 & $<0,0001$ & 5,3 \\
\hline $2-11^{*}$ & 114 & 58 & 41 & 76 & 18 & 92 & 1,69 & 0,0348 & 10,8 \\
\hline $3-1$ & 120 & 66 & 46 & 83 & 38 & 95 & 3,80 & $<0,0001$ & 6,2 \\
\hline $3-3$ & 120 & 46 & 33 & 61 & 12 & 92 & 1,25 & 0,2109 & 12,3 \\
\hline $3-4^{*}$ & 120 & 59 & 43 & 75 & 31 & 92 & 1,46 & 0,0916 & 12,0 \\
\hline $3-5 *$ & 120 & 53 & 38 & 76 & 32 & 83 & 3,60 & $<0,0001$ & 7,0 \\
\hline $3-7^{*}$ & 120 & 54 & 45 & 71 & 30 & 82 & 2,43 & 0,0008 & 7,4 \\
\hline $4-1 *$ & 104 & 73 & 61 & 94 & 48 & 100 & 3,02 & 0,0001 & 5,2 \\
\hline $4-2$ & 104 & 60 & 48 & 73 & 10 & 79 & 2,08 & 0,0081 & 6,8 \\
\hline $4-12 *$ & 103 & 40 & 31 & 54 & 15 & 71 & 1,81 & 0,0263 & 9,7 \\
\hline $4-13^{*}$ & 104 & 61 & 49 & 72 & 40 & 81 & 2,16 & 0,0057 & 5,5 \\
\hline $4-14$ & 104 & 58 & 50 & 66 & 36 & 79 & 2,04 & 0,0098 & 4,5 \\
\hline $5-3 *$ & 96 & 23 & 14 & 39 & 3 & 48 & 2,13 & 0,0086 & 19,4 \\
\hline $5-4$ & 92 & 48 & 40 & 57 & 27 & 87 & 1,06 & 0,4115 & 9,5 \\
\hline $5-10^{*}$ & 96 & 68 & 58 & 86 & 53 & 94 & 7,37 & $<0,0001$ & 3,8 \\
\hline $5-14^{*}$ & 96 & 51 & 39 & 68 & 19 & 74 & 2,85 & 0,0004 & 9,0 \\
\hline $5-15^{*}$ & 92 & 58 & 45 & 70 & 11 & 80 & 1,98 & 0,0178 & 8,3 \\
\hline $5-16^{*}$ & 96 & 29 & 20 & 41 & 14 & 53 & 2,02 & 0,0133 & 12,3 \\
\hline $6-14$ & 96 & 66 & 52 & 81 & 25 & 96 & 2,20 & 0,0063 & 7,5 \\
\hline $7-14$ & 96 & 70 & 48 & 96 & 28 & 118 & 5,46 & $<0,0001$ & 6,3 \\
\hline $8-15^{*}$ & 112 & 70 & 58 & 81 & 54 & 85 & 4,61 & $<0,0001$ & 3,7 \\
\hline
\end{tabular}

(1)Ano: 1, 1987/1988; 2, 1988/1989; 3, 1989/1990; 4, 1990/1991; 5, 1991/1992; 6, 1992/1993; 7, 1993/1994; 8, 1994/1995; Local: 1, Iraí; 2, Frederico Westphalen; 3, Canguçu; 4, Erechim; 5, Osório; 6, Sobradinho; 7, Pelotas; 8, Capão do Leão; 9, Cruz Alta; 10, Santa Maria; 11, Coronel Bicaco; 12, Arroio do Tigre; 13, Júlio de Castilhos; 14, Sarandi; 15, Passo Fundo; 16, Santo Augusto. *Ambientes em que o efeito de estande sobre o rendimento foi significativo. 
semeadura para alcançar uniformidade de estande inicial em torno de 72 plantas, a variação do estande final foi bastante elevada.

Considerando-se o estande por unidade experimental, num total de 3.608 parcelas, a variação da redução em relação ao estande ideal foi ainda mais acentuada, com extremos de 95,8\% (3 plantas) e -63,9\% (118 plantas). Entretanto, em apenas $5,5 \%$ das parcelas, a redução foi superior a $60 \%$, enquanto $21 \%$ das parcelas apresentaram estande final acima do ideal. Ainda que este valor seja bastante inferior ao porcentual de parcelas com estande abaixo do ideal (76\%), a redução do estande pode ter origem no erro experimental, como efeito de características estranhas associadas à semente (vigor, sanidade), e em diferenças de adaptabilidade dos genótipos. O considerável porcentual de parcelas com estande acima do ideal pode ter duas explicações: a primeira, o método de ajuste do número de sementes, baseado no teste de germinação em laboratório, não é eficiente para alcançar a uniformidade do estande inicial, por não ser um bom preditor da germinação no campo, e a segunda, esse método é eficiente, mas não foi empregado de modo correto em todos os ambientes. Em qualquer dessas situações, são evidenciadas a necessidade e a importância de identificar e eliminar as causas da desuniformidade do estande inicial em experimentos de feijão, que podem comprometer a validade das inferências sobre os genótipos. Com relação às análises da variação do estande, observou-se que, em 28 ambientes (85\% do total), o efeito de genótipos sobre o estande foi significativo.

Na Tabela 2, são apresentados os resultados da análise de co-variação entre rendimento e estande final para cada ambiente, considerando a interação genótipo $\mathrm{x}$ estande. Verificou-se que em 10 (30\%) dos 33 ambientes os efeitos linear e quadrático do estande sobre o

Tabela 2. Principais resultados das análises de co-variação entre rendimento e estande final, considerando as interações entre genótipo e os efeitos linear e quadrático do estande, para os 33 ambientes.

\begin{tabular}{|c|c|c|c|c|c|c|}
\hline $\begin{array}{l}\text { Ambiente }^{(1)} \\
\text { (ano-local) }\end{array}$ & $\begin{array}{c}\text { Rend. médio } \\
\text { (gramas por parcela) }\end{array}$ & $\begin{array}{l}\text { Estande } \\
\text { médio }\end{array}$ & $\begin{array}{l}\text { Efeito linear } \\
\text { Prob. }>\mathrm{F}\end{array}$ & $\begin{array}{c}\text { Efeito quadrático } \\
\text { Prob. }>\mathrm{F}\end{array}$ & $\begin{array}{l}\text { Gen. } x \text { Linear } \\
\text { Prob. }>\text { F }\end{array}$ & $\begin{array}{c}\text { Gen. x Quadrático } \\
\text { Prob. }>\text { F }\end{array}$ \\
\hline $1-1^{*}$ & 561 & 71 & 0,0144 & 0,6251 & 0,0460 & 0,4336 \\
\hline $1-2 *$ & 323 & 70 & 0,4719 & 0,0739 & 0,0141 & 0,0076 \\
\hline $1-3 *$ & 437 & 48 & 0,4883 & 0,0415 & 0,1120 & 0,1015 \\
\hline $1-5^{*}$ & 748 & 84 & 0,0002 & 0,6377 & 0,2272 & 0,4974 \\
\hline $1-6^{*}$ & 342 & 66 & 0,0029 & 0,5460 & 0,7252 & 0,7056 \\
\hline $1-7 *$ & 503 & 51 & 0,0154 & 0,6983 & 0,3846 & 0,1028 \\
\hline $2-2$ & 300 & 39 & $<0,0001$ & 0,0943 & 0,4952 & 0,5549 \\
\hline $2-3 *$ & 99 & 60 & 0,0058 & 0,7604 & 0,2144 & 0,3433 \\
\hline $2-5^{*}$ & 629 & 67 & 0,7204 & 0,0056 & 0,7354 & 0,6537 \\
\hline $2-7 *$ & 490 & 56 & 0,8892 & 0,9307 & 0,1398 & $-(2)$ \\
\hline $2-8^{*}$ & 336 & 54 & 0,0704 & 0,1796 & 0,8546 & 0,4133 \\
\hline $2-9$ & 319 & 65 & $<0,0001$ & 0,1664 & 0,6318 & 0,6917 \\
\hline $2-10 *$ & 720 & 75 & 0,7623 & 0,7518 & 0,2369 & 0,2328 \\
\hline $2-11 *$ & 626 & 58 & $<0,0001$ & 0,5559 & 0,0460 & 0,2864 \\
\hline $3-1 *$ & 500 & 66 & 0,4319 & 0,9423 & 0,0755 & 0,2234 \\
\hline $3-3$ & 230 & 46 & 0,5278 & 0,4466 & 0,8059 & 0,6730 \\
\hline $3-4$ & 727 & 59 & 0,0238 & 0,0218 & 0,1169 & 0,6418 \\
\hline $3-5^{*}$ & 726 & 53 & 0,0232 & 0,9890 & 0,6761 & 0,1618 \\
\hline $3-7 *$ & 491 & 54 & 0,0204 & 0,0612 & 0,8171 & 0,3792 \\
\hline $4-1 *$ & 460 & 73 & $<0,0001$ & 0,0021 & 0,2011 & 0,7313 \\
\hline $4-2 *$ & 478 & 60 & 0,2672 & 0,5506 & 0,2998 & 0,7481 \\
\hline $4-12 *$ & 449 & 40 & 0,0004 & 0,2997 & 0,2115 & 0,5789 \\
\hline $4-13 *$ & 321 & 61 & $<0,0001$ & 0,1886 & 0,5278 & 0,4527 \\
\hline $4-14 *$ & 369 & 58 & 0,2056 & 0,7551 & 0,8083 & 0,7652 \\
\hline $5-3 *$ & 501 & 23 & $<0,0001$ & 0,0017 & 0,3349 & 0,7830 \\
\hline $5-4$ & 841 & 48 & 0,0471 & 0,9630 & 0,0074 & 0,1069 \\
\hline $5-10^{*}$ & 736 & 68 & 0,0078 & 0,4925 & 0,7909 & 0,5696 \\
\hline $5-14 *$ & 641 & 51 & 0,0001 & 0,1842 & 0,3672 & 0,4118 \\
\hline $5-15^{*}$ & 738 & 58 & 0,0100 & 0,5373 & 0,6248 & 0,7704 \\
\hline $5-16^{*}$ & 411 & 29 & 0,0007 & 0,0128 & 0,1733 & 0,0779 \\
\hline $6-14 *$ & 553 & 66 & 0,3102 & 0,6294 & 0,7641 & 0,6671 \\
\hline $7-14 *$ & 524 & 70 & 0,3161 & 0,3461 & 0,3325 & 0,1661 \\
\hline $8-15^{*}$ & 583 & 70 & 0,0100 & 0,7531 & 0,8502 & 0,7962 \\
\hline
\end{tabular}

(1)Ano: 1, 1987/1988; 2, 1988/1989; 3, 1989/1990; 4, 1990/1991; 5, 1991/1992; 6, 1992/1993; 7, 1993/1994; 8, 1994/1995; Local: 1, Iraí; 2, Frederico Westphalen; 3, Canguçu; 4, Erechim; 5, Osório; 6, Sobradinho; 7, Pelotas; 8, Capão do Leão; 9, Cruz Alta; 10, Santa Maria; 11, Coronel Bicaco; 12, Arroio do Tigre; 13, Júlio de Castilhos; 14, Sarandi; 15, Passo Fundo; 16, Santo Augusto. ${ }^{(2)}$ Ambiente com número de observações insuficiente para testar a interação. *Ambientes em que o efeito de genótipos sobre o estande foi significativos. 
rendimento foram não-significativos; em 17 ambientes (52\%), apenas o efeito linear do estande foi significativo; em dois ambientes $(6 \%)$, apenas o efeito quadrático do estande foi significativo; e em quatro ambientes (12\%), os efeitos linear e quadrático foram significativos. Contrariando os resultados de Ribeiro et al. (2004a), foi observado nos ambientes em que o efeito de estande foi significativo, uma redução média de plantas em relação ao estande ideal, variando de $-16,7$ a $68,1 \%$; isto sugere que, em qualquer nível de redução de plantas, o rendimento de grãos pode ser afetado pelo estande. Com relação à hipótese de homogeneidade dos coeficientes de regressão, em apenas quatro ambientes (12\%) a interação estande $\mathrm{x}$ genótipo foi significativa. Nos seis ambientes (1-3, 2-5, 3-4, 4-1, 5-3 e 5-16) em que o efeito quadrático ou ambos os efeitos, linear e quadrático, foram significativos, os ajustamentos foram realizados segundo o modelo linear-quadrático.

Quanto ao processo de agrupamento dos genótipos, nos ambientes em que o efeito de genótipos sobre o estande foi significativo, observou-se que o teste de Scott-Knott com nível de significância 0,05 formou grupos em 79\% dos ambientes; com nível de significância 0,10, em 90\% dos ambientes; e com nível de significância 0,20 , em todos os 28 ambientes. Os agrupamentos formados no nível de significância 0,20 foram validados em 97\% dos ambientes, pela comparação com resultados do teste $\mathrm{F}$ para efeitos de grupos, que foram significativos, e de genótipos dentro de grupos, que foram não-significativos.

$\mathrm{Na}$ análise do rendimento, deve-se distinguir a variação entre genótipos que decorre dos efeitos diretos dos genótipos da variação que resulta do efeito dos genótipos sobre o estande. Os modelos propostos para ajustamento do rendimento têm o propósito de levar em conta o efeito do genótipo sobre o estande. Na Tabela 3, são apresentados os resultados obtidos, para todos os ambientes, pelas análises segundo cada um dos quatro modelos propostos, exceto para o Modelo 4 nos ambientes em que não houve formação de grupos.

Esses resultados revelam que a precisão dos experimentos (expressa pelo CV) aumentou em $82 \%$ dos ambientes, quando procedido ao ajuste do rendimento pelo estande. Verifica-se também que no modelo linear, a precisão não se alterou entre as três formas de ajustamentos (Modelos 2, 3 e 4). Esse fato é consequiência da propriedade de que os resíduos desses ajustamentos são iguais. Com relação ao efeito dos genótipos sobre o rendimento de grãos, verifica-se que, em geral, não ocorreram alterações expressivas de níveis de significâncias (expressos pelos valores p) entre os quatro procedimentos de análise. Embora na maioria dos ambientes $(61 \%)$ todos os ajustamentos do rendimento para a variação do estande tenham aumentado o valor da estatística F, em apenas um ambiente (1-6), essa alteração tornou significativo $(p=0,0417)$ o efeito de genótipo que era não-significativo $(\mathrm{p}=0,1248)$ na análise sem ajuste.

Um dos quatro modelos apresentados (Tabela 1) é o mais apropriado para cada ambiente particular. Nos dez ambientes em que os efeitos linear e quadrático do estande sobre o rendimento foram não-significativos (1-2, 2-7, 2-10, 3-1, 3-3, 4-2, 4-14, 5-4, 6-14 e 7-14), o Modelo 1 é apropriado. Nos três ambientes em que pelo menos um dos efeitos, linear ou quadrático, do estande sobre o rendimento foi significativo, mas o efeito de genótipos sobre o estande foi não-significativo (2-2, 2-9 e 3-4), o Modelo 2 é adequado. Todavia, nos 20 ambientes em que a variação do estande entre genótipos e o efeito linear ou quadrático do estande sobre o rendimento foi significativo (1-1, 1-3, 1-5, 1-6, 1-7, 2-3, 2-5, 2-8, 2-11, 3-5, 3-7, 4-1, 4-12, 4-13, 5-3, 5-10, 5-14, 5-15, 5-16 e 8-15), não há como decidir entre o ajuste do rendimento para a média geral de estande (Modelo 2) e o ajuste para as médias de genótipos (Modelo 3 ) ou de grupos de genótipos (Modelo 4). Observe-se, entretanto, que, caso houvesse certeza de que essa variação do estande se devesse exclusivamente ao efeito de genótipos, a formação de grupos de genótipos para todos esses ambientes conduziria à escolha do Modelo 4 .

A Tabela 4 contém o resumo dos resultados das análises realizadas no ambiente 1-1 (1987/1988 - Iraí), escolhido para ilustrar a situação observada com maior freqüência no conjunto total de ambientes: significância dos efeitos de estande sobre o rendimento e de genótipos sobre o estande. Nesse ambiente, o efeito linear do estande sobre o rendimento foi significativo $(p=0,0256)$ e o efeito de genótipo sobre o estande foi altamente significativo $(p=0,0086)$. Ele apresentou um dos estandes médios mais altos: 71 plantas; entretanto, seu rendimento médio não foi tão alto (561 gramas por parcela), ocupando a 12a posição entre os 33 ambientes.

Os valores extremos para a redução do estande médio de genótipo em relação ao estande ideal foram 35,4\% (50 plantas) e -20,8\% (87 plantas); entretanto, $53 \%$ das médias de estande situaram-se dentro do intervalo $72 \pm 10 \%$ plantas. Com relação ao rendimento, o ajuste pela média geral do estande provocou alterações nas médias de genótipos que variaram de $-7,8$ a 10,0\%. Essas alterações fizeram com que o efeito de genótipo, que 
era não-significativo na análise sem ajuste, se tornasse significativo com o ajustamento. Foi observado, também, que esse ajustamento modificou a ordenação de 78,8\% dos genótipos. Considerando os resultados relativos ao ajuste pelos estandes médios de grupos, as alterações nos rendimentos médios foram menos acentuadas, variando de $-4,4$ a 5,6\%. Esse ajustamento alterou a ordem de 54,4\% dos genótipos, mas o efeito de genótipo sobre o rendimento permaneceu não-significativo após o ajuste.

A significância do efeito linear do estande indica que algum ajuste do rendimento pela variação do estande deve ser efetuado. Entretanto, a falta de informação sobre a origem da variação do estande entre genótipos não permite identificar qual modelo é mais apropriado. Observa-se, na análise sem ajuste, que os genótipos com estandes mais baixos apresentaram rendimentos relativamente altos. Isto pode ser decorrente do fato de a relação linear entre rendimento e estande não ter sido muito significativa, e parece ser uma evidência do efeito compensatório do feijão.

A fim de ilustrar o impacto que o ajustamento do rendimento para o estande pode provocar nas inferências sobre genótipos, foi realizado, no ambiente 5-3 (1991/ 1992 - Canguçu), o agrupamento dos genótipos segundo seus rendimentos pelo teste de Scott-Knott, que é

Tabela 3. Resultados das análises da variação do rendimento (em gramas por parcela) e da co-variação do rendimento em relação ao estande, para os 33 ambientes.

\begin{tabular}{|c|c|c|c|c|c|c|c|c|c|c|c|c|}
\hline \multirow{4}{*}{$\begin{array}{l}\text { Ambiente }^{(1)} \\
\text { (ano-local) }\end{array}$} & \multirow{2}{*}{\multicolumn{3}{|c|}{ Sem ajuste }} & \multicolumn{9}{|c|}{ Com ajuste para } \\
\hline & & & & \multicolumn{3}{|c|}{ Estande médio geral } & \multicolumn{3}{|c|}{ Estande médio de genótipo } & \multicolumn{3}{|c|}{ Estande médio de grupo } \\
\hline & \multirow{2}{*}{$\begin{array}{l}\mathrm{CV} \\
(\%)\end{array}$} & \multicolumn{2}{|c|}{ Genótipo } & \multirow{2}{*}{$\begin{array}{l}\mathrm{CV} \\
(\%)\end{array}$} & \multicolumn{2}{|c|}{ Genótipo } & \multirow{2}{*}{$\begin{array}{l}\mathrm{CV} \\
(\%) \\
\end{array}$} & \multicolumn{2}{|c|}{ Genótipo } & \multirow{2}{*}{$\begin{array}{l}\mathrm{CV} \\
(\%)\end{array}$} & \multicolumn{2}{|c|}{ Genótipo } \\
\hline & & $\mathrm{F}$ & Prob $>F$ & & $\mathrm{~F}$ & Prob $>F$ & & $\mathrm{~F}$ & Prob $>F$ & & $\mathrm{~F}$ & Prob $>F$ \\
\hline $1-1 * *$ & 22,6 & 1,49 & 0,0820 & 22,1 & 1,73 & 0,0273 & 22,1 & 1,56 & 0,0604 & 22,1 & 1,55 & 0,0633 \\
\hline $1-2$ & 27,3 & 1,82 & 0,0179 & 27,4 & 1,76 & 0,0236 & 27,4 & 1,80 & 0,0194 & 27,4 & 1,80 & 0,0193 \\
\hline $1-3 * *$ & 14,0 & 3,17 & $<0,0001$ & 13,9 & 3,31 & $<0,0001$ & 13,6 & 3,52 & $<0,0001$ & 13,7 & 3,44 & $<0,0001$ \\
\hline $1-5^{* *}$ & 16,1 & 4,87 & $<0,0001$ & 14,9 & 5,52 & $<0,0001$ & 14,9 & 5,75 & $<0,0001$ & 14,9 & 5,72 & $<0,0001$ \\
\hline $1-6^{* *}$ & 19,5 & 1,39 & 0,1248 & 18,3 & 1,37 & 0,1342 & 18,3 & 1,57 & 0,0571 & 18,3 & 1,64 & 0,0417 \\
\hline $1-7 * *$ & 22,2 & 2,03 & 0,0063 & 21,6 & 1,91 & 0,0113 & 21,6 & 2,13 & 0,0038 & 21,6 & 2,09 & 0,0048 \\
\hline $2-2 *$ & 34,4 & 1,92 & 0,0110 & 31,0 & 1,96 & 0,0088 & 31,0 & 2,36 & 0,0012 & $-^{(2)}$ & - & - \\
\hline $2-3 * *$ & 32,0 & 3,64 & $<0,0001$ & 30,5 & 4,17 & $<0,0001$ & 30,5 & 4,06 & $<0,0001$ & 30,5 & 4,17 & $<0,0001$ \\
\hline $2-5 * *$ & 18,2 & 1,78 & 0,0213 & 17,4 & 1,59 & 0,0516 & 17,6 & 1,88 & 0,0132 & 18,2 & 1,67 & 0,0363 \\
\hline $2-7$ & 21,1 & 2,40 & 0,0023 & 21,3 & 2,36 & 0,0028 & 21,3 & 2,36 & 0,0028 & 21,3 & 2,36 & 0,0028 \\
\hline $2-8$ & 17,8 & 3,86 & $<0,0001$ & 17,4 & 3,89 & $<0,0001$ & 17,4 & 4,01 & $<0,0001$ & 17,4 & 3,91 & $<0,0001$ \\
\hline $2-9 *$ & 18,7 & 6,53 & $<0,0001$ & 15,2 & 10,30 & $<0,0001$ & 15,2 & 9,86 & $<0,0001$ & 15,2 & 10,94 & $<0,0001$ \\
\hline $2-10$ & 19,1 & 4,43 & $<0,0001$ & 19,2 & 4,37 & $<0,0001$ & 19,2 & 4,38 & $<0,0001$ & 19,2 & 4,36 & $<0,0001$ \\
\hline $2-11 * *$ & 21,8 & 5,10 & $<0,0001$ & 19,0 & 6,59 & $<0,0001$ & 19,0 & 6,76 & $<0,0001$ & 19,3 & 6,62 & $<0,0001$ \\
\hline $3-1$ & 20,4 & 2,89 & $<0,0001$ & 20,4 & 2,48 & 0,0006 & 20,4 & 2,87 & $<0,0001$ & 20,4 & 2,81 & 0,0001 \\
\hline $3-3$ & 20,0 & 2,01 & 0,0069 & 20,1 & 1,98 & 0,0080 & 20,1 & 2,00 & 0,0074 & - & - & - \\
\hline $3-4^{*}$ & 13,6 & 4,55 & $<0,0001$ & 13,1 & 4,90 & $<0,0001$ & 12,2 & 5,99 & $<0,0001$ & 12,7 & 5,27 & $<0,0001$ \\
\hline $3-5 * *$ & 13,8 & 2,81 & 0,0001 & 13,5 & 2,67 & 0,0002 & 13,5 & 2,95 & $<0,0001$ & 13,5 & 2,97 & $<0,0001$ \\
\hline $3-7 * *$ & 25,1 & 1,10 & 0,3526 & 24,4 & 1,12 & 0,3408 & 24,4 & 1,17 & 0,2836 & 24,4 & 1,19 & 0,2556 \\
\hline $4-1 * *$ & 17,7 & 4,82 & $<0,0001$ & 14,5 & 6,21 & $<0,0001$ & 15,1 & 6,47 & $<0,0001$ & 15,3 & 5,18 & $<0,0001$ \\
\hline $4-2$ & 19,5 & 2,55 & 0,0010 & 19,4 & 2,55 & 0,0010 & 19,4 & 2,56 & 0,0010 & 19,4 & 2,58 & 0,0009 \\
\hline $4-12 * *$ & 24,3 & 2,08 & 0,0082 & 22,2 & 2,26 & 0,0037 & 22,2 & 2,52 & 0,0012 & 22,3 & 2,26 & 0,0038 \\
\hline $4-13 * *$ & 26,2 & 1,38 & 0,1419 & 21,5 & 2,75 & 0,0004 & 21,5 & 2,05 & 0,0092 & 21,5 & 2,21 & 0,0047 \\
\hline $4-14$ & 21,3 & 2,26 & 0,0036 & 21,1 & 2,23 & 0,0043 & 21,1 & 2,29 & 0,0032 & 21,1 & 2,23 & 0,0042 \\
\hline $5-3 * *$ & 26,0 & 2,12 & 0,0090 & 17,1 & 2,80 & 0,0006 & 18,0 & 4,58 & $<0,0001$ & 17,2 & 5,67 & $<0,0001$ \\
\hline $5-4$ & 22,1 & 0,76 & 0,7562 & 21,9 & 0,78 & 0,7411 & 21,9 & 0,78 & 0,7388 & - & - & - \\
\hline $5-10 * *$ & 19,8 & 2,58 & 0,0013 & 18,6 & 2,26 & 0,0051 & 18,6 & 2,91 & 0,0003 & 18,6 & 2,92 & 0,0003 \\
\hline $5-14 * *$ & 25,5 & 2,23 & 0,0067 & 22,1 & 3,01 & 0,0002 & 22,1 & 3,24 & $<0,0001$ & 22,1 & 3,65 & $<0,0001$ \\
\hline $5-15^{* *}$ & 16,6 & 3,18 & 0,0001 & 15,7 & 3,11 & 0,0002 & 15,7 & 3,59 & $<0,0001$ & 15,7 & 3,22 & 0,0001 \\
\hline $5-16 * *$ & 20,4 & 2,31 & 0,0039 & 18,6 & 2,46 & 0,0023 & 19,1 & 2,71 & 0,0008 & 19,2 & 2,62 & 0,0012 \\
\hline $6-14$ & 23,7 & 4,09 & $<0,0001$ & 23,6 & 3,66 & $<0,0001$ & 23,6 & 4,11 & $<0,0001$ & 23,6 & 3,89 & $<0,0001$ \\
\hline $7-14$ & 21,6 & 1,90 & 0,0216 & 21,6 & 1,58 & 0,0763 & 21,6 & 1,90 & 0,0222 & 21,6 & 1,84 & 0,0282 \\
\hline $8-15 * *$ & 13,4 & 5,76 & $<0,0001$ & 12,7 & 5,82 & $<0,0001$ & 12,7 & 6,38 & $<0,0001$ & 12,7 & 6,07 & $<0,0001$ \\
\hline Média & 21,1 & 2,91 & & 19,7 & 3,20 & & 19,8 & 3,43 & & 19,4 & 3,56 & \\
\hline Mínimo & 13,4 & 0,76 & & 12,7 & 0,78 & & 12,2 & 0,78 & & 12,7 & 1,19 & \\
\hline Máximo & 34,4 & 6,53 & & 31,0 & 10,30 & & 31,0 & 9,86 & & 30,5 & 10,94 & \\
\hline
\end{tabular}

(1)Ano: 1, 1987/1988; 2, 1988/1989; 3, 1989/1990; 4, 1990/1991; 5, 1991/1992; 6, 1992/1993; 7, 1993/1994; 8, 1994/1995; Local: 1, Iraí; 2, Frederico Westphalen; 3, Canguçu; 4, Erechim; 5, Osório; 6, Sobradinho; 7, Pelotas; 8, Capão do Leão; 9, Cruz Alta; 10, Santa Maria; 11, Coronel Bicaco; 12, Arroio do Tigre; 13, Júlio de Castilhos; 14, Sarandi; 15, Passo Fundo; 16, Santo Augusto. (2)Ambientes em que não houve formação de grupos pelo teste de Scott-Knott $(\alpha=0,20)$. *Ambientes com efeito significativo de estande sobre o rendimento. **Ambientes com efeito significativo de estande sobre rendimento e de genótipo sobre estande. 
utilizado com frequiência em ensaios de comparação de médias de genótipos. Nesse ambiente, os efeitos linear e quadrático do estande sobre o rendimento e o efeito de genótipo sobre o estande foram todos altamente significativos. Na Tabela 5, são apresentados os resultados dos testes de agrupamento dos rendimentos médios de genótipos, segundo os modelos Modelos 1,2 e 4, considerando o efeito linear-quadrático do estande. O Modelo 2 diferiu pouco do Modelo 1 quanto à discriminação dos genótipos, pois ambos permitiram a formação de dois grupos de constituições muito semelhantes, embora a classificação dos genótipos dentro dos grupos tenha variado entre os modelos. Entretanto, com o ajuste do rendimento segundo o Modelo 4, foram formados cinco grupos, o que significa maior discriminação dos genótipos. Esse ajuste remove o efeito de estande nas parcelas com mesmo genótipo, mas não nas parcelas com genótipos diferentes cujos efeitos sobre o estande não diferem. As diferenças entre os resultados referentes aos Modelos 2 e 4 indicam a

Tabela 4. Resultados das análises do ambiente 1-1 (1987/1988 - Iraí), em que o efeito linear do estande sobre o rendimento e o efeito de genótipo sobre o estande foram significativos.

\begin{tabular}{|c|c|c|c|c|c|c|}
\hline \multirow[t]{3}{*}{ Grupo $^{(1)}$} & \multirow[t]{3}{*}{ Genótipo $^{(2)}$} & \multirow[t]{3}{*}{ Estande médio } & \multicolumn{4}{|c|}{ Rendimento (gramas por parcela) ${ }^{(3)}$} \\
\hline & & & \multirow[t]{2}{*}{ Sem ajuste } & \multicolumn{3}{|c|}{ Com ajuste } \\
\hline & & & & $\begin{array}{c}\text { Estande médio } \\
\text { geral }\end{array}$ & $\begin{array}{c}\text { Estande médio } \\
\text { de genótipo }\end{array}$ & $\begin{array}{c}\text { Estande médio } \\
\text { de grupo }\end{array}$ \\
\hline 1 & Turrialba 4 & 87 & 601 (10) & $555(15)$ & $601(10)$ & $575(12)$ \\
\hline 1 & Iraí & 86 & 613 (9) & $570 \quad(12)$ & 613 (9) & $591 \quad(10)$ \\
\hline 1 & Tahyu & 84 & $488 \quad(25)$ & $450 \quad(28)$ & $488 \quad(25)$ & 470 (27) \\
\hline 1 & RAI-72 & 82 & $560(15)$ & $529 \quad(18)$ & $560 \quad(15)$ & $549(16)$ \\
\hline 1 & A-227 & 82 & $553(16)$ & $521 \quad(20)$ & $553(16)$ & $541(18)$ \\
\hline 1 & CNF 0158 & 81 & 533 (19) & $503 \quad(22)$ & 533 (19) & $523(20)$ \\
\hline 1 & CNF 5494 & 80 & $707 \quad(1)$ & $681 \quad(6)$ & $707 \quad(1)$ & $701 \quad(2)$ \\
\hline 1 & BAT 429 & 79 & $520 \quad(21)$ & $498 \quad(23)$ & $520 \quad(21)$ & $518(21)$ \\
\hline 1 & Capixaba Precoce & 79 & 471 (27) & 449 (29) & 471 (27) & 469 (28) \\
\hline 1 & EEP-527 & 78 & 483 (26) & $462 \quad(25)$ & $483 \quad(26)$ & $482(25)$ \\
\hline 1 & A-236 & 78 & $512(22)$ & $490 \quad(24)$ & $512 \quad(22)$ & $510 \quad(22)$ \\
\hline 1 & Guateian 6662 & 76 & $425 \quad(30)$ & $410 \quad(30)$ & 425 & $430 \quad(30)$ \\
\hline 1 & EMPASC 201 & 74 & $528 \quad(20)$ & $519 \quad(21)$ & $528 \quad(20)$ & 539 (19) \\
\hline 1 & FT 83-25 & 74 & $536(18)$ & $527 \quad(19)$ & $536 \quad(18)$ & 547 (17) \\
\hline 1 & CNF 3993 & 72 & 547 (17) & $545 \quad(17)$ & 547 (17) & 565 (14) \\
\hline 1 & LM 30074 & 72 & $648 \quad(5)$ & $646 \quad(7)$ & $648 \quad(5)$ & $666 \quad(5)$ \\
\hline 1 & FT 84-398 & 71 & 576 (12) & $577 \quad(11)$ & 576 (12) & $597 \quad$ (9) \\
\hline 1 & FT Tarumã & 69 & $448 \quad(28)$ & $453 \quad(26)$ & $448 \quad(28)$ & $473 \quad(26)$ \\
\hline \multicolumn{2}{|c|}{ Média do grupo } & 78 & - & - & - & - \\
\hline 2 & CNF 5493 & 69 & 563 (14) & $569 \quad(13)$ & 563 (14) & $555 \quad(15)$ \\
\hline 2 & Maquiné & 68 & 584 (11) & 594 & $584 \quad(11)$ & $579 \quad(11)$ \\
\hline 2 & FT 120 & 67 & $618 \quad(8)$ & $629 \quad(8)$ & $618 \quad(8)$ & $615 \quad(8)$ \\
\hline 2 & CNF 3465 & 66 & $671 \quad(4)$ & 686 & $671 \quad(4)$ & $672 \quad(4)$ \\
\hline 2 & FT $84-158$ & 66 & 573 (13) & $588 \quad(10)$ & 573 (13) & 574 (13) \\
\hline 2 & CNF 5483 & 64 & $696 \quad(2)$ & 716 & $696 \quad(2)$ & $702 \quad(1)$ \\
\hline 2 & Rio Tibagi & 63 & $429 \quad(29)$ & $452 \quad(27)$ & $429 \quad(29)$ & $438 \quad(29)$ \\
\hline \multicolumn{2}{|c|}{ Média do grupo } & 66 & - & - & - & - \\
\hline 3 & FT 84-86 & 55 & $510 \quad(23)$ & $555 \quad(14)$ & $510 \quad(23)$ & $503 \quad(23)$ \\
\hline 3 & LM 20785 & 54 & 497 (24) & $546 \quad(16)$ & $497 \quad(24)$ & $494 \quad(24)$ \\
\hline 3 & Rio Negro & 53 & $630 \quad(6)$ & $682 \quad(5)$ & $630 \quad(6)$ & $629 \quad(7)$ \\
\hline 3 & LM 30063 & 52 & $687 \quad(3)$ & 741 & 687 & 688 \\
\hline 3 & Carioca & 50 & $622 \quad(7)$ & 684 & 622 & $632 \quad(6)$ \\
\hline \multicolumn{2}{|c|}{ Média do grupo } & 53 & - & - & - & - \\
\hline \multicolumn{2}{|c|}{ Média geral } & 71 & 561 & 561 & 561 & 561 \\
\hline $\mathrm{CV}(\%)$ & & 7,6 & 22,6 & 22,1 & 22,1 & 22,1 \\
\hline QM Erro & & 0,4043 & 16.124 & 15.388 & 15.388 & 15.388 \\
\hline QM genó & & 1,6579 & 23.964 & 26.623 & 23.964 & 23.800 \\
\hline F genótip & & 4,10 & 1,49 & 1,73 & 1,56 & 1,55 \\
\hline P genótip & & $<0,0001$ & 0,0820 & 0,0273 & 0,0604 & 0,0633 \\
\hline QM co-ve & iável & - & - & 79.426 & 79.426 & 79.426 \\
\hline F co-vari & & - & - & 5,16 & 5,16 & 5,16 \\
\hline P co-vari & & - & - & 0,0256 & 0,0256 & 0,0256 \\
\hline
\end{tabular}

${ }^{(1)}$ Grupos de genótipos formados segundo seus estandes médios, pelo teste de Scott-Knott $(\alpha=0,20)$. (2) Os genótipos CNF 5494 e CNF 5493 tornaram-se cultivares (Macanudo e Pampa, respectivamente) em 1989. (3) Valores entre parênteses expressam a classificação relativa de cada genótipo. 
Tabela 5. Resultados dos testes de agrupamento dos rendimentos médios de genótipos para três ajustamentos, segundo o modelo linear-quadrático, para o ambiente 5-3 (1991/1992 - Canguçu).

\begin{tabular}{|c|c|c|c|c|c|c|c|c|}
\hline \multirow{4}{*}{$\begin{array}{l}\text { Genótipo }^{(1)} \\
\text { IAPAR } 31\end{array}$} & \multirow{4}{*}{$\begin{array}{c}\text { Cor do grão } \\
\text { De cor }\end{array}$} & \multirow{4}{*}{$\begin{array}{c}\begin{array}{c}\text { Tipo de } \\
\text { planta }\end{array} \\
\text { II }\end{array}$} & \multicolumn{6}{|c|}{ Rendimento (gramas por parcela) $^{(2)}$} \\
\hline & & & \multirow{2}{*}{\multicolumn{2}{|c|}{ Sem ajuste }} & \multicolumn{4}{|c|}{ Com ajuste } \\
\hline & & & & & \multicolumn{2}{|c|}{$\begin{array}{c}\text { Estande } \\
\text { médio geral }\end{array}$} & \multicolumn{2}{|c|}{$\begin{array}{l}\text { Estande médio de grupos de } \\
\text { genótipos }\end{array}$} \\
\hline & & & $723 \mathrm{a}$ & $(1)$ & $668 \mathrm{a}$ & (1) & $746 \mathrm{a}$ & $(1)$ \\
\hline CNF 5490 & Preto & III & $625 a$ & (2) & $568 \mathrm{a}$ & (5) & $647 b$ & $(2)$ \\
\hline CNF 5491 & Preto & II & $574 a$ & (5) & $550 \mathrm{a}$ & (7) & $641 b$ & (3) \\
\hline FT $85-206$ & De cor & II & $603 a$ & (4) & $555 \mathrm{a}$ & (6) & $639 b$ & (4) \\
\hline FT 86-206 & Preto & II & $608 \mathrm{a}$ & (3) & $542 \mathrm{a}$ & (9) & $619 \mathrm{~b}$ & (5) \\
\hline FT 89-103 & Preto & II & $542 a$ & $(8)$ & $471 \mathrm{~b}$ & (16) & $544 c$ & $(6)$ \\
\hline C $87-2198$ & Preto & III & $492 \mathrm{a}$ & (16) & $457 b$ & (18) & $540 \mathrm{c}$ & (7) \\
\hline Rio Tibagi (T) & Preto & II & $520 \mathrm{a}$ & (11) & $460 \mathrm{~b}$ & (17) & $540 \mathrm{c}$ & (8) \\
\hline Minuano & Preto & III & $543 a$ & (7) & $592 \mathrm{a}$ & (2) & $536 \mathrm{c}$ & (9) \\
\hline EMPASC $201(\mathrm{~T})$ & Preto & II-III & $510 \mathrm{a}$ & (15) & $572 a$ & (3) & $513 d$ & (10) \\
\hline Carioca $(\mathrm{T})$ & De cor & III & $513 a$ & (14) & $569 a$ & (4) & $507 \mathrm{~d}$ & (11) \\
\hline $86-533$ & De cor & III & $541 \mathrm{a}$ & (9) & $546 a$ & (8) & $502 d$ & (12) \\
\hline Capixaba precoce $(\mathrm{T})$ & Preto & II & $533 a$ & (10) & $536 \mathrm{a}$ & (11) & $490 \mathrm{~d}$ & (13) \\
\hline Tahyu & De cor & II-III & $520 \mathrm{a}$ & (12) & $541 \mathrm{a}$ & (10) & $488 \mathrm{~d}$ & (14) \\
\hline MP 8971 & Preto & II & $554 a$ & (6) & $428 b$ & (19) & $480 \mathrm{~d}$ & (15) \\
\hline LA 720230 & Preto & II & $513 a$ & (13) & $408 \mathrm{~b}$ & (22) & $470 \mathrm{~d}$ & (16) \\
\hline FT 120 & Preto & II & $421 \mathrm{~b}$ & (18) & $498 \mathrm{~b}$ & (12) & $447 d$ & (17) \\
\hline Macanudo & Preto & III & $403 b$ & (19) & $488 \mathrm{~b}$ & (14) & $425 \mathrm{e}$ & (18) \\
\hline Barriga verde & Preto & II-III & $376 b$ & (22) & $496 b$ & (13) & $423 \mathrm{e}$ & (19) \\
\hline Pampa & Preto & II & $422 b$ & (17) & $474 b$ & (15) & $417 \mathrm{e}$ & (20) \\
\hline Iraí & De cor & I & $395 b$ & (20) & $415 b$ & (20) & $364 \mathrm{e}$ & (21) \\
\hline Guateian $6662(\mathrm{~T})$ & Preto & II-III & $393 b$ & (21) & $410 \mathrm{~b}$ & (21) & $361 \mathrm{e}$ & (22) \\
\hline $86-1210$ & Preto & III & $368 b$ & (23) & $398 b$ & (23) & $353 \mathrm{e}$ & (23) \\
\hline IAPAR 44 & Preto & II & $338 b$ & (24) & $388 \mathrm{~b}$ & (24) & $339 \mathrm{e}$ & (24) \\
\hline
\end{tabular}

${ }^{(1)}$ T: cultivar testemunha. ${ }^{(2)}$ Valores entre parênteses expressam a classificação relativa de cada genótipo; médias seguidas por letras distintas constituem grupos diferentes, pelo teste de Scott-Knott $(\alpha=0,20)$.

importância da escolha correta do ajustamento para cada ambiente, só possível mediante conhecimento seguro da origem da variação do estande entre genótipos. Esse fato salienta a importância do registro de todas as ocorrências relevantes durante a execução do experimento, e, particularmente, o registro do estande inicial.

Os resultados evidenciam que a consideração do estande e particularmente o ajustamento do rendimento para a variação do estande podem aperfeiçoar o processo de avaliação nos programas de melhoramento de feijão. Por sua vez, a não-significância do efeito de estande sobre o rendimento em alguns ambientes sugere que existe um efeito compensatório do feijão quando a redução do estande não é extrema, o que já havia sido relatado por vários autores (Adams, 1967; Fernandes et al., 1989; Valério et al., 1999; Shimada, 2000; Teixeira et al., 2000; Ribeiro et al., 2004a, 2004b). Nesses casos, não há necessidade do ajuste.

\section{Conclusões}

1. O rendimento de grãos de genótipos de feijão pode ser afetado por variações do estande final e o estande final manifesta variação entre genótipos.
2. O estande deve ser considerado no planejamento e na análise de experimentos regionais de melhoramento genético do feijão.

3. Devem ser adotadas técnicas de pesquisa que evitem confundimento tendencioso de efeito de genótipos sobre o estande com efeito de erro experimental.

4. É necessário o registro de informações que permitam identificar e discriminar a origem da variação sistemática do estande.

5. O ajuste do rendimento para a variação do estande final é importante e os efeitos de genótipos sobre o estande final devem ser considerados neste ajuste.

\section{Agradecimentos}

À Capes e ao CNPq, pela concessão de bolsas; à Fundação de Apoio a Pesquisa e Desenvolvimento Agropecuário Edmundo Gastal (Fapeg), pelo apoio financeiro.

\section{Referências}

ADAMS, M.W. Basis of yield component compensation in crop plants with special reference to the field bean, Phaseolus vulgaris L. Crop Science, v.7, p.505-510, 1967. 
ANDRADE, H.B.; RAMALHO, M.A.P.; BUENO FILHO, J.S. de S.; RESENDE, M.D.V. de; XAVIER, A.; SCOLFORO, J.R.S. Alternativas para atenuar a diferença de estande nos experimentos de avaliação de clones de Eucalyptus urophylla. Revista Árvore, v.30, p.11-18, 2006.

CARGNELUTTI FILHO, A.; STORCK, L. Métodos de correção da produtividade de grãos de milho relacionados à adaptabilidade e estabilidade de cultivares. Pesquisa Agropecuária Brasileira, v.39, p.857-864, 2004.

DIDONET, A.D.; COSTA, J.G.C. População de plantas e rendimento de grãos em feijoeiro comum de ciclo precoce. Pesquisa Agropecuária Tropical, v.34, p.105-109, 2004.

FERNANDES, M.I.P.S.; RAMALHO, M.A.P.; LIMA, P.C. Comparação de métodos de correção em estandes de feijão. Pesquisa Agropecuária Brasileira, v.24, p.997-1002, 1989.

INSTITUTO DE PESQUISAS AGRONÔMICAS. Recomendações para a cultura do feijão. Porto Alegre: Secretaria da Agricultura, 1986. 46p.

JADOSKI, S.O.; CARLESSO, R.; WOISCHICK, D.; PETRY, M.T.; FRIZZO, Z. População de plantas e espaçamento entre linhas do feijoeiro irrigado. II: Rendimento de grãos e componentes do rendimento. Ciência Rural, v.30, p.567-573, 2000.

RIBEIRO, N.D.; CARGNELUTTI FILHO, A.; HOFFMANN JÚNIOR, L.; POSSEBON, S.B. Precisão experimental na avaliação de cultivares de feijão de diferentes hábitos de crescimento. Ciência Rural, v.34, p.1371-1377, 2004b.

RIBEIRO, N.D.; CARGNELUTTI FILHO, A.; JOST, E.; POERSCH, N.L.; TRENTIN, M. Alterações em caracteres agromorfológicos em função da densidade de plantas em cultivares de feijão. Revista Brasileira de Agrociência, v.10, p.167-173, 2004a. SCHMILDT, E.R.; CRUZ, C.D.; ZANUNCIO, J.C.; PEREIRA, P.R.G.; FERRÃO, R.G. Avaliação de métodos de correção de estande para estimar a produtividade em milho. Pesquisa Agropecuária Brasileira, v.36, p.1011-1018, 2001.

SCOTT, A.J.; KNOTT, M.A. A cluster analysis method for grouping means in the analysis of variance. Biometrics, v.30, p.507-512, 1974.

SHIMADA, M.M.; ARF, O.; SÁ, M.E.Componentes do rendimento e desenvolvimento do feijoeiro de porte ereto sob diferentes densidades populacionais. Bragantia, v.59, p.181-187, 2000.

STORCK, L.; LOPES, S.J.; MARQUES, D.G.; TISSOT, C.A.; ROS, C.A. da. Análise de co-variância para melhoria da capacidade de discriminação em ensaios de cultivares de milho. Pesquisa Agropecuária Brasileira, v.35, p.1311-1316, 2000.

TEIXEIRA, I.R.; ANDRADE, M.J.B. de; CARVALHO, J.G. de; MORAIS, A.R. de; CORRÊA, J.B.D. Resposta do feijoeiro (Phaseolus vulgaris L. cv. Pérola) a diferentes densidades de semeadura e doses de nitrogênio. Ciência e Agrotecnologia, v.24, p.399-408, 2000.

VALÉRIO, C.R.; ANDRADE, M.J.B.; FERREIRA, D.F. Comportamento das cultivares de feijão aporé, carioca e pérola em diferentes populações de plantas e espaçamentos entre linhas. Ciência e Agrotecnologia, v.23, p.515-528, 1999.

VENCOVSKY, R.; CRUZ, C.D. Comparação de métodos de correção do rendimento de parcelas com estandes variados: I. Dados simulados. Pesquisa Agropecuária Brasileira, v.26, p.647-657, 1991.

VERONESI, J.A.; CRUZ, C.D.; CORRÊA, L.A.; SCAPIM, C.A. Comparação de métodos de ajuste do rendimento de parcelas com estandes variados. Pesquisa Agropecuária Brasileira, v.30, p.169174, 1995.

ZUBER, M.S. Relative efficiency of incomplete block designs using corn uniform trial data. Journal of the American Society of Agronomy, v.34, p.30-47, 1942. 